\title{
The missing link between flood risk awareness and preparedness: findings from case studies in an Alpine Region
}

\author{
A. Scolobig ${ }^{1,2}$ \\ B. De $\mathrm{Marchi}^{3}$
}

M. Borga ${ }^{4}$

1. ISIG-Institute of International Sociology of Gorizia; Mass Emergencies Programme, Via Mazzini n. 13, I-34170 Gorizia

2. IIASA-International Institute for Applied Systems Analysis, Risk, Policy and Vulnerability Program Schlossplatz 1 A-2361 Laxenburg

${ }^{3}$ SVT-Centre for the Study of the Sciences and the Humanities, University of Bergen, Allégt 34, N-5007 Bergen.

${ }^{4}$ Department of Land and Agroforest Environments; University of Padova, Agripolis, I-35020 Legnaro (PD)

\section{Citation}

Scolobig A., De Marchi B., Borga M. (2012), "The missing link between flood risk awareness and preparedness. Findings from case studies in an Italian Alpine Region", Natural Hazards, 63(2): 499-520. doi: 10.1007/s11069-012-0161-1

\begin{abstract}
The low risk awareness of the residents living in flood prone areas is usually considered among the main causes of their low preparedness, which in turns generates inadequate response to natural disasters. In this paper we challenge this assumption by reporting on the results of a sociological research in four communities exposed to flood risk in the Eastern Italian Alps. The research design included semi-structured interviews and focus groups with key local stakeholders and a standardised questionnaire submitted to 400 residents. Results revealed that residents felt both slightly worried about flood risk and slightly prepared to face an event. Considerable differences were found between the evaluations of individual subjects as opposed to overall communities. There was also a clear discrepancy between the actual adoption of household preparatory measures and the willingness to take self-protection actions. Overall, the risk awareness was significantly higher among those residents who had been personally affected by a flood in the past, were living in isolated (vs. urban) communities, in the most risky areas, or had a lower level of trust in local authorities. The improvement of residents' knowledge about their environment and the residual risk seemed to be crucial to increase risk awareness and the same was true for the strengthening of local support networks to foster preparedness. The link between risk awareness and preparedness was not at all straightforward. Results revealed instead the complexity of residents' perspectives, attitudes, behaviours, and decisions about risk related issues.
\end{abstract}

Keywords: flood risk awareness, preparedness, attitude-behaviour link, communication strategies 


\section{Introduction}

Residents' low risk awareness and preparedness may hinder an effective response in case of a natural disaster, thus becoming key issues to be considered for effective emergency planning and management. A common assumption is that the residents' low risk awareness is among the main causes of an insufficient level of preparedness, which in turn generates inadequate response to disasters. This assumption is supported by several scientific and policy documents (e.g. Terpstra et al. 2009; Miceli et al. 2008; Grothmann and Reusswig 2006; Water Directors of the European Union 2002). Several research results (e.g. Terpstra et al. 2009; Miceli et al. 2008; Grothmann and Reusswig 2006) indicate that disaster preparedness is positively associated with the feeling of worry about the risk. Similarly, the willingness to adopt precautionary measures is positively related in many cases with the residents' level of risk awareness (Neuwirth et al. 2000; Floyed et al. 2000).

The logic behind the examples reported above is that awareness of risk automatically translates into an actual behaviour (i.e. adoption of precautionary measures/actions) or influences its adoption. However, even if strong attitudes and beliefs can be catalysts of behaviour change, the link between the two should not be taken for granted as shown by other researches in the field of natural hazards (Gruntfest 1987; Weinstein et al. 2000; Paton et al. 2000). The report of a research commissioned by the UK Environment Agency reveals that: "The link between awareness-raising and response is not straightforward and the extent to which awareness-raising activities can replace flood experience in improving preparedness is unclear" (Cave et al. 2009:37). Also other social/psychological studies not necessarily related to risk (e.g. la Piere 1934; Ajzen and Fishbein 1980; Fazio and Williams 1986; Ross et al.1981; Eagly and Chaiken 1993; Petty and Krosnick 1995; Cialdini 2001; Marsch and Wallace 2005) show how attitudes are not always good behaviour predictors.

In this paper we deal with these issues by presenting the findings from case studies in an Italian Alpine region. We focus on natural hazards, and more precisely on flash floods and debris flows. The high risk potential of flash floods is related to their rapid occurrence and to the spatial dispersion of the areas which may be impacted by these floods (Borga et al. 2010). Both characteristics limit our ability to issue timely flood warnings. Short available time for hazard anticipation requires preparedness and response management by organisations and people (Borga et al. 2011; Ruin et al. 2008; Creutin et al. 2009).

In the first part of the paper we provide a short literature review on the main aspects which influence the way people live with and frame flood risk, focusing on the results of selected previous investigations on risk awareness and preparedness and showing that the relationship between the 
two is less straightforward than it might be expected. After describing the study sites, the research design and methodology, we concentrate on the analysis of the residents' risk perception, their level of preparedness, the main factors influencing their motivation for taking (or not taking) preventive actions and the (missing) relationship between risk awareness and preparedness. Finally we discuss the implications of these results for communication strategies and future research.

\section{Flood risk as a social construct}

The way people live with risk has been the main topic of risk perception studies since the late sixties (Starr 1969; Slovic 1987). Since then, many publications have appeared with contributions from several disciplines such as psychology (e.g. Slovic 1987; 2000), anthropology (e.g. Douglas and Wildawsky 1982; Douglas 1985) and sociology (e.g. Beck 1992). These approaches focus alternatively on the role played by individual cognitive frames, cultural aspects and worldviews, social norms and beliefs, political and institutional structures in influencing the way people conceptualize risk. Overall, the proponents of such approaches explore how people collect, select and interpret information about the impacts of possible events, using direct or indirect observations. Their results reveal that perceptions may differ depending on the type of risk and its characteristics, but also on individual personality traits and the socio-cultural context (e.g. Fischhoff et al. 1979; Slovic 1987, 2000; Douglas and Wildawsky 1982; Beck 1992; Johnston and Covello 1987; Jasanoff 1998; Strydrom 2002). In other words, risk is a social construct and people frame it in different ways. Not only views about risk change among different people, but even the same person may change his/her views over time.

The "classical" psychological or anthropological approaches mentioned above have not been often adopted for floods (see e.g. Hoeckstra 1998; Plapp 2001; Plapp and Werner 2006; Terpstra et al. 2009). Many studies and researchers focused on flood risk perception use these "classical" approaches as a reference point, but in practice they follow "nested" approaches (Wachinger et al. 2010) by alternatively attributing relevance to cognitive, affective, social, economic, cultural and/or contextual factors or their reciprocal interactions in defining the way people live with these natural events (e.g. Baan and Klijn 2004; Tapsell et al. 2002; Burningham et al. 2008).

One common finding (e.g. Baan and Klijn 2004; Tapsell et al. 2002) is that people usually show limited concern about flood risk for several reasons. The first (and most intuitive one) is the lack of knowledge/information. To be worried, a person needs to know that he/she lives in a risky area. Often the hazard associated with raising waters is "indiscernible", because there are no visual clues that may alert to the presence of a risk: people don't see raising waters in their everyday life and, as a consequence, they assume that the hazard is negligible (Burningham et al. 2008). 
Skiple Ibreek et al. (2005) showed that less than half the inhabitants of a floodplain in the United States were aware of the flood risk. The same was found in the UK (Kundzewicz and Mendel 2003). Fordham (1992) suggested that inhabitants of floodplains most frequently take decisions in a condition of ignorance of their exposure, and the problem increases in case of migratory movements to floodplains (Llasat and Siccardi 2010).

Even if a person knows of living in a hazardous area, he/she may not feel worried for many different reasons linked to personality traits, cultural, social or economic factors (McCarthy et al., 2008). A large body of research underlines the relevance of optimistic or "normalisation" biases, i.e. the tendency to underestimate hazard based on cognitive factors rather than evidence (e.g. Mileti and O'Brien 1992; Deeming 2008). This may be the case even with the experience of minor past events, which may lead to underestimate the likelihood and impact of a major, rare or exceptional event (Green et al. 1991; Kundzewicz and Mendel 2003). Mileti and O'Brien (1992) describe this way of reasoning in the following way: "If in the past the event did not hit me negatively, I will escape also negative consequences of future events" (1992, 53). Also, other ways of reasoning such as "Nothing worse could happen" or "It won't happen again" may be related to this process of normalisation (Deeming 2008).

Other authors (Stefanovic 2003; Baan and Klijn 2004) mention the "crisis effect" for events with severe consequences: it seems that a flood is a catalyst for a higher risk awareness which peaks during and immediately after an event, but rapidly dissipates afterwards. Actually the influence of a previous flood experience on risk awareness has been pointed out by many authors (e.g. Green et al. 1991; Tapsell and Tunstall 2007), but it is still unclear if this is proportionate to the amount of economic and social disruption.

Another finding regards the relation between the existence of flood protection structures and the induced collateral effect of lower risk awareness among the local people (Dynes 1974; Burby and French 1981; Bye and Horner 1998; Handmer 2000; Enserink 2004; Morris and Sinclair 2005). Some authors define this as the "levee effect" (e.g. Baan and Klijn 2004), referring to the fact that once flood structural devices are in place, people place unrestrained and often inappropriate faith in their protection capability and "seem to be lulled into thinking the levee will protect them against all future floods" (Baan and Klijn 2004).

Finally economic factors may also play a critical role in influencing peoples' evaluations about the risk. Admitting the existence of a risk is often equivalent to "an acknowledgement of the devaluation of the home, a recognition that the latter may be uninsurable or even unsalable" (Harries, 2008). Risk denial thus can be a "safer" psychological attitude than having to cope with practical problems derived from its acknowledgment. Therefore the low risk evaluations may be the 
result of quite complex mental constructs, which include actual economic constraints as well as many other aspects. Among these, the role played by the institutional aspects and their interplay with the scientific ones (e.g. risk analysis and assessment) seem to be under-researched. For example the decisions about building constraints in risk areas or about risk mapping could definitely influence how people conceptualise the risk. Also place attachment, feeling of belonging or local knowledge can induce people to be more optimistic about risk evaluations (Tapsell and Tunstall 2008).

In summary, as shown in this brief literature review, research results are in most cases quite scattered and fragmented. A consistent framework is still lacking which identifies the main aspects influencing the way people conceptualise flood risk and cope with it (Wachinger et al. 2010).

\section{Attitudes and behaviours: from risk awareness to preparedness}

The hypothesis we wanted to test in our research is that the way people frame risk represents a good predictor of the actions they undertake to face adverse events. For example if people underestimate the intensity of a flood they may not take the necessary cautionary actions to protect themselves. If people overestimate a hazard instead, they may spend far too many resources on reducing an only minimal risk (Wachinger et al. 2010).

Research results are quite contradictory (Miceli et al. 2008; Grothmann and Reusswig 2006; Siegrist and Gutscher 2006). In this section we focus on such results starting with the preparedness process. When dealing with the residents' preparedness, researchers consider at least two different dimensions: the psychological and the physical one (Tierney et al. 2001; Handmer 2000). The former refers to a mind-set attentive to danger sources and oriented to anticipating and addressing the problems which are likely to appear in future emergency situations, also taking into account personal strengths and weaknesses, including the availability or lack of mutual aid networks. Physical preparedness consists instead in a series of precautionary measures such as the securing of property and goods from events such as rising water or debris flow. Some research findings reveal that, if adopted by the residents in flood prone areas, these measures "can reduce monetary flood damage by $80 \%$, and thus reduce the need for public risk management" (Grothmann and Reusswig 2006). The example of Cologne in Germany, which was impacted by two flood events in 1993 and 1995, is often reported to document the impact of preparedness on flood losses. More precisely, Fink et al. (1996) reveal that "given similar exposure $(10.63 \mathrm{~m}$ level in 1993; $10.69 \mathrm{~m}$ water level in 1995) and almost the same sensitivity (similar property value affected), losses from two severe floods fell from about 65 billion $€$ in 1993 to 30 billion $€$ in 1995 . The damage prevention efforts 
undertaken by the residents appear to account for most of the difference in monetary losses" (Fink et al. 1996: 37).

Notwithstanding this consistent decrease in losses, several researchers reported that people living in areas exposed to natural disasters do very little or nothing at all to limit the risk of death, injury, or property damage (Peek and Mileti 2002). Overall "research on the causes for such 'under-reaction' is rare, especially in Europe" (Grothmann and Reusswig 2006), but there is a growing interest to better understand the reasons why people do get prepared or not, and to identify the determinants of damage prevention actions (e.g. Tapsell et al. 1999; Grothmann and Reusswig 2006; Siegrist and Gutscher 2008; Harries 2008).

The role played by risk awareness in influencing preparedness is not clear. Some researchers found a direct relationship between the two (e.g. Miceli et al. 2008; Grothmann and Reusswig 2006), whilst others found no such relationship (Siegrist and Gutscher 2006; Kuhlicke and Steinfuehrer 2007). Similar contradictory results can be found for other natural disasters: for example Lindell and Whitney (2000) found no significant correlation between perception of earthquake risk and the adoption of seismic hazard adjustments among a sample of university students living in California. Further studies conducted on samples of persons exposed to tornadoes (Weinstein et al. 2000) and volcanic hazards (Paton et al. 2000) provided similar results.

In other words, the relationship between risk awareness and preparedness is less straightforward than one might expect and different hypotheses need testing. By challenging the assumption that "preparedness is the result of risk awareness" we want to open this black box with the purpose to better understand what lies behind these concepts and their often over-simplified relationships. This was one of the aims of the research illustrated in the following sections.

\section{Study sites and research design}

Our research was carried out in four sites located in the Adige/Sarca river basin in the Eastern Italian Alps (Fig. 1): Bocenago, Roverè della Luna, Romagnano and Vermiglio-Rio Cortina. 


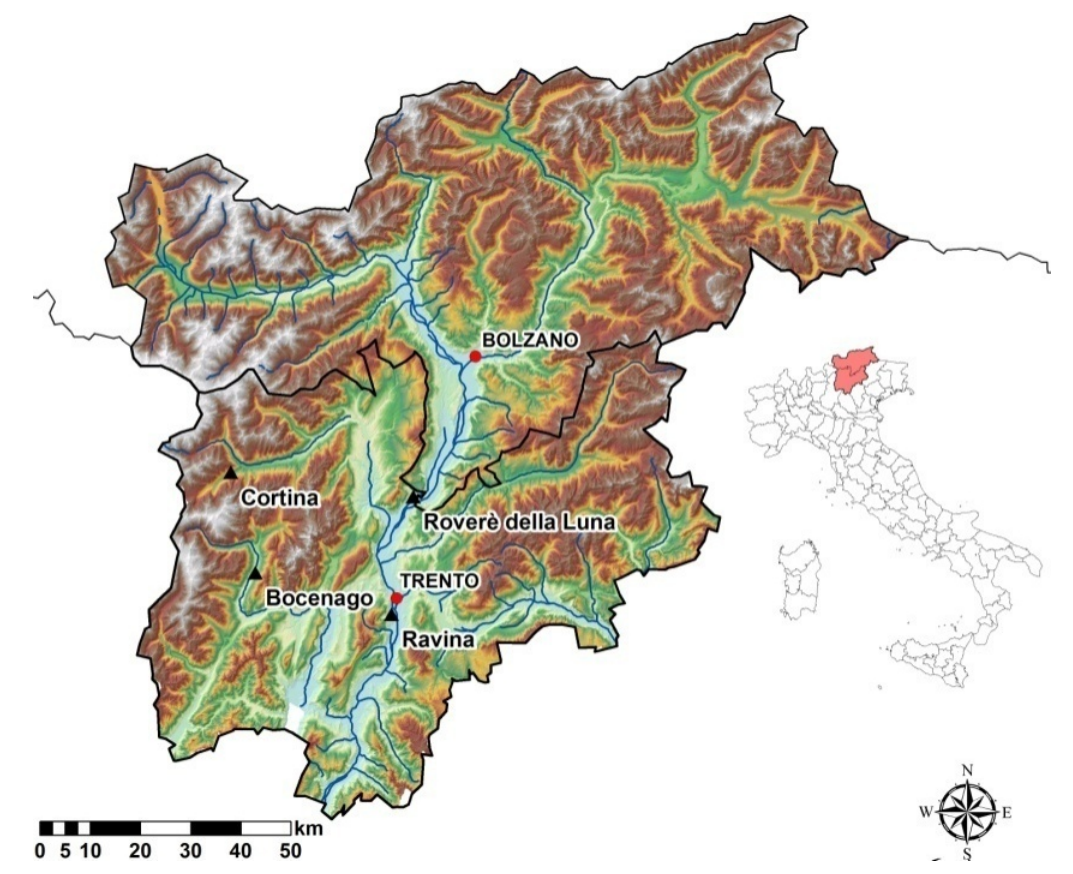

From an administrative point of view, they are all located in the Province of Trento, Italy. The four sites were severely impacted by two flood episodes which occurred in the Autumn of the years 2000 and 2002. In both years, the Autumn had been characterised by continuous rainfall. With such wet antecedent soil moisture conditions, even non record-breaking precipitation events were able to generate extreme runoff responses associated to landslides and debris flows. Norbiato et al. (2008) and Marchi et al. (2010) provide an account of the impact of initial soil moisture conditions on the triggering of flash floods under European conditions.

In Bocenago (372 inhabitants, $750 \mathrm{~m}$ a.s.1.) the severe precipitation of November 26, 2002 triggered a large landslide which impacted a number of buildings in the town. On the night of November 19, 2000, the town of Romagnano (1,272 inhabitants, $220 \mathrm{~m}$ a.s.1.) was severely impacted by a debris flow which flowed for $200 \mathrm{~m}$ before damaging a number of buildings and then depositing in the central square, which was fortunately empty. A deep landslide event impacted Roverè della Luna (1,472 inhabitants, $300 \mathrm{~m}$ a.s.1.) in the period between 15 and 20 November 2000 and a large part of the local population was evacuated to manage the risk due to the landslide process. Vermiglio-Rio Cortina (1,856 inhabitants, $1200 \mathrm{~m}$ a.s.1.) was impacted by two debris flows, the first on November 17, 2000, and the second on November 14, 2002. In the first case three bridges were destroyed and about 100 people were evacuated for a few days. Part of the population was evacuated also during the second episode.

In all the municipalities in the area simulation exercises are organised periodically by the technical offices and the local fire brigades, in cooperation with police, red cross and other organisations, depending on each case. Voluntary local fire brigades have a very strong tradition in the entire 
region and are constantly supported by provincial agencies dealing with risk management. Each municipality has an emergency plan which is updated through time and in some cases includes risk information campaigns or other communication activities.

The fieldwork coordinated by the Institute of International Sociology of Gorizia (ISIG) in the selected municipalities started in 2005 and lasted for one year. The research design foresaw the triangulation of standard and non-standard methods. By "standard method" we mean one in which tools and procedures are codified and shared and the reduction of complexity is achieved through the data matrix where the observations are systematically reported. The qualification of "nonstandard" method identifies instead a collection of approaches, techniques and tools which require a number of decisions and skills from the part of the researcher, whose interactive relationship with its object of study is clearly acknowledged (Marradi 2007).

Techniques of data collection included: exploration of data from existing sources, such as census data and provincial archives; 4 focus groups and 22 semi-structured interviews (with officers from census services and agencies in charge of civil protection, risk prevention, water resources, hydrology, community leaders, politicians, scientific and technical experts, members of nongovernmental organisation); a questionnaire survey carried out interviewing face-to-face a total of 400 local residents, 100 in each site. In many phases of the research, participant observations was used: we repeatedly visited the sites and spent time talking to residents, local authorities, fire brigades members, and other witnesses in order to develop an idea of the structural and cultural traits of the communities.

The questionnaire was prepared on the basis of a review of the existing literature and the results of the documentary analysis, focus groups, semi-structured interviews. Several aspects were considered, ranging from the residents' flood experience to their opinions about risk mitigation measures. The questionnaire included 147 items, and the responses to most of them were constructed as 5 point Likert scales, where 1 represented the minimum value and 5 the maximum one. Among the numerous sections of the questionnaire, two were devoted to the analysis of risk awareness and preparedness.

With regard to our sampling procedure, a context-specific methodology was required to select the respondents, due to the spatial characteristics of flood hazard in the study sites. The expert analysis of the flood processes allows to map the hazard in a number of classes, based on the hydrological/hydraulic features of the flood, the topography and land use of the area. Thus, in each site the sample was drawn as to include quotas of respondents selected according to the level of flood hazard exposure (high, medium, low) of their houses. The other variables considered were gender, age, and education. This procedure was necessary since a random sample might have 
resulted in the exclusion or under-representation of precisely those residents we were particularly interested in, i.e. those living in the riskiest areas. While the distribution of the population according to demographic variables was available through the municipal administrations, that of flood hazard was provided by the technical offices on the basis of hazards/risk maps (when available) or by expert consultations. The unit of analysis was the individual and interviewees were instructed to contact only one person per household.

Survey data from closed-ended questions was coded and then treated with SPSS (Statistical Package for the Social Sciences), whereas "qualitative answers" (derived from open-ended questions or spontaneous additions to the pre-defined items of response) were categorized/aggregated and then subsequently transformed into quantitative data amenable to treatment with SPSS.

In the data analysis we used a set of 26 independent variables for cross-tabulation to test any statistically significant relationships. We divided the independent variables in several subsets, reported in Tab. 1 (for an overview see De Marchi et al. 2007).

Tab.1 - Set of independent variables

\begin{tabular}{|c|c|c|c|c|c|}
\hline Set & Variables & Set & Variables & Set & Variables \\
\hline \multirow[t]{5}{*}{ Place } & Research location & \multirow{5}{*}{$\begin{array}{l}\text { Socio } \\
\text { demographic }\end{array}$} & Gender & \multirow{5}{*}{$\begin{array}{l}\text { Flood event } \\
\text { experience }\end{array}$} & Advice networks \\
\hline & Place of work/residence & & Age & & Support networks \\
\hline & Risk exposure & & Educational qualification & & Support index \\
\hline & Length of residence & & \multirow[t]{2}{*}{ Occupation } & & Flood impact \\
\hline & Other place of residence & & & & Evacuation \\
\hline \multirow[t]{4}{*}{ Household } & Household income & \multirow[t]{4}{*}{ Social capital } & In fire brigade & \multirow[t]{4}{*}{ Personal history } & $\begin{array}{l}\text { Previous flood } \\
\text { experience }\end{array}$ \\
\hline & House ownership & & Community embedding & & Trust in local authorities \\
\hline & $\begin{array}{l}\text { Family with dependent } \\
\text { persons }\end{array}$ & & Social networks' type & & Risk awareness \\
\hline & $\begin{array}{l}\text { Family with persons in } \\
\text { need }\end{array}$ & & Social networks' location & & Personal preparedness \\
\hline
\end{tabular}

\section{Research results}

In the following sections we will deal with the residents' behaviors, judgments, attitudes and opinions related to flood risk. How do people evaluate and frame it? How do they get prepared? How do they evaluate their level of preparedness? Which are the motivations behind their evaluations? Which kind of preparatory measures do they adopt? The results of the questionnaire survey with the residents will provide some answers to these questions. 


\section{Risk awareness}

We were interested in exploring if the respondents were aware of the flood risk before the most recent events took place and if they thought that something similar might happen again. We also investigated the feeling of danger/threat induced by flood events. In most cases, we asked the respondents to explain the reasons for their answers (in an open-ended form) so that we could gain a more complete picture of their conceptual framing of the risk.

We are aware that these a-posteriori answers are likely to be filtered through the previous flood experience. On the other hand, in the impossibility of conducting surveys in real time, it must be accepted that accounts of past experiences are inevitably an individual work of reconstruction and interpretation. In any case, as we were interested in possible changes in attitudes and behaviours in connection with the experience of floods, we repeated a few questions about awareness and preparedness twice, in exactly in the same format, except the time framing (indeed, prior to and after the events).

Respondents were first asked: "Before the event, did you think that something of that kind might happen here?". The percentage of "yes" is $43.8 \%$ and is only slightly higher $(48 \%)$ when the question is asked again in relation to a possible similar occurrence in the future (Tab. 2).

Tab.2 - Evaluations about possible occurrence of events

\begin{tabular}{|c|c|c|c|}
\hline Questions & Yes & No & $\begin{array}{l}\text { Don't } \\
\text { know }\end{array}$ \\
\hline Before the event, did you think that something of that kind might happen here? & 43.8 & 54.8 & 1.4 \\
\hline Do you think a similar event might happen here again? & 48 & 38.8 & 13.3 \\
\hline
\end{tabular}

Some insights for the interpretation of these results emerge from cross-tabulation of the evaluations about possible occurrence of events with our set of independent variables (as reported in Tab. 1). Statistically significant relations have been detected with the following independent variables: previous flood experience, trust in local authorities and research location.

As shown in Table 3, among those that had a previous flood experience (previous to the one in the years 2000 or 2002 - depending on the research site) there is a higher percentage of "aware" respondents both before and after the events, with respect to those that had no such experience. The relation with another independent variable, level of trust in the local authorities, is more difficult to interpret. This variable is actually an index we constructed by combining three questions assessing trust in civil protection, voluntary organisations, and municipal authorities. Results reveal that among those with a higher level of trust there is a lower percentage of "aware" respondents. We 
found a similar inverse relation between the level of trust and the feeling of danger related to floods or flash floods (see Tab.6).

It seems that trust (or perhaps confidence, Giddens 1990) in the authorities in charge is accompanied by a tendency to discount danger and become less risk aware. This relation needs to be further explored also because of its implications for communication and policy. The reliance on professional agencies and services is well grounded in the area of our research, as these are well organized and highly efficient. However this (correct) positive assessment from the part of residents may translate into an overestimation of their actual capacities and resources, to the point of a total delegation of responsibility.

The last independent variable is the research location: in the communities rather isolated and far from urban areas (i.e. Vermiglio-Rio Cortina and Bocenago) people were more aware about the possible occurrence of hydrological dangerous events. Also on the basis of local visits and interactions, we feel that this might be related to a deeper familiarity with one's territory, derived from long time residence and inter-generational transmission of knowledge and experience.

Tab. 3- Results of the cross-tabulation between the questions about event occurrence and the set of independent variables

\begin{tabular}{|l|c|c|}
\hline & Awareness of events before & Awareness of possible future events \\
\hline Previous flood experience & ${ }^{*}(.000)$ & ${ }^{*}(.043)$ \\
\hline Trust in local authorities & ${ }^{*}(.000)$ & ${ }^{*}(.003)$ \\
\hline Study site & $*(.000)$ & \\
\hline
\end{tabular}

*: significant correlation

Chi square values in brackets

To the respondents in all the four sites who appeared to show a certain risk awareness $(43.8 \%)$, we asked to explain where it was grounded. We presented them with a set of possible reasons, and for each they had to indicate whether it was pertinent or not: previous similar events, environmental signs (signals), official information (Tab. 4). We also gave them the possibility to indicate other alternatives, not present in our list. More precisely, we aimed at investigating the "sources of knowledge" and in particular the supposedly rare but precious ability to detect alerting signals to an impending disaster in the environment. As expected, such skill appeared far from common, being indicated by less than $30 \%$ of respondents. These referred not only to the most evident warning signal, i.e. heavy rain, but also to changes in streams and/or rivers such as increased quantity of water, muddy appearance, presence of debris or obstructions.

In any event, the main drive for risk awareness is the previous experience of similar events, indicated by $90 \%$ of the respondents (similar findings in Parker et al. 2011). This result is consistent with those reported above about the role played by previous flood experience in relation to thoughts about possible future occurrences. A very small minority (5\%) mentioned "official information". 
This sounds discouraging, as this is an area where information activities have been undertaken with some continuity. Interestingly enough, $12 \%$ of respondents used the opportunity (normally discarded in this and other surveys) to add other alternatives of their own thinking, besides the ones suggested by the investigators. These refer mainly to local knowledge about past events based on oral transmission. A few interviewees also provided technically-focused explanations referring to the peculiar morphology of the area.

Tab. 4 - Motivations for awareness before the events

\begin{tabular}{|c|c|c|c|c|}
\hline \multicolumn{5}{|c|}{ Awareness due to: } \\
\hline $\begin{array}{c}\text { Previous } \\
\text { (similar) events }\end{array}$ & $\begin{array}{c}\text { Official } \\
\text { information }\end{array}$ & $\begin{array}{c}\text { Environmental } \\
\text { signals }\end{array}$ & $\begin{array}{c}\text { Other } \\
\text { source }\end{array}$ & Total \\
\hline$\%$ & $\%$ & $\%$ & $\%$ & $\mathrm{~N}$ \\
\hline 88.8 & 5.0 & 28.6 & 12.4 & 161 \\
\hline
\end{tabular}

The results described so far are consistent with the ones about the evaluation of the danger at community, home and individual level. The answers to the question "Do you think that these events are a danger/threat to your physical integrity?" resulted in a mean value of 1.7 on a five point Likert scale ( 1 min and 5 max, see Table 5). The same question relating to one's home and the entire village/town obtained higher mean values (1.95 and 2.65 respectively). There seems to be a hiatus between the evaluation of danger at the individual and the community level, with an inclination to underestimate the former.

Tab.5 - Feeling of danger related to flash floods/debris flows

\begin{tabular}{|l|r|r|}
\hline Questions & $\begin{array}{c}\text { Mean } \\
\text { value }\end{array}$ & \multicolumn{1}{|c|}{$\mathbf{N}^{*}$} \\
\hline $\begin{array}{l}\text { [On a scale from } 1 \text { (min) to } 5 \text { (max)] Do you think flash floods/debris flows are a danger for___ (name } \\
\text { village)? }\end{array}$ & 2.65 \\
\hline $\begin{array}{l}\text { [On a scale from } 1 \text { (min) to } 5 \text { (max)] Do you think flash floods/debris flows are a danger for your home (where } \\
\text { you live)? }\end{array}$ & 1.95 \\
\hline $\begin{array}{l}\text { [On a scale from } 1 \text { (min) to } 5 \text { (max)] Do you think flash floods/debris flows are a danger for your physical } \\
\text { integrity? }\end{array}$ & 1.70 \\
\hline
\end{tabular}

* "Don't know" answers have been excluded

Again, some insights for the interpretation of these results emerge from the cross-tabulation with our set of independent variables. 
Tab.6 - Results of the cross-tabulation between danger evaluations and the set of independent variables

\begin{tabular}{|l|c|c|c|}
\hline & $\begin{array}{l}\text { Flash floods/debris flows: } \\
\text { danger for the entire } \\
\text { village/town }\end{array}$ & $\begin{array}{l}\text { Flash floods/debris flows: } \\
\text { danger for one's home }\end{array}$ & $\begin{array}{l}\text { Flash floods/debris flows: } \\
\text { danger for one's physical } \\
\text { integrity }\end{array}$ \\
\hline Risk exposure & $*{ }^{*}(.072)$ & ${ }^{*}(.053)$ \\
\hline Flood impact & ${ }^{*}(.050)$ & ${ }^{*}(.049)$ & ${ }^{*}(.066)$ \\
\hline Trust in local authorities & ${ }^{*}(.041)$ & ${ }^{*}(.025)$ & ${ }^{*}(.025)$ \\
\hline Study site & ${ }^{*}(.091)$ & & \\
\hline
\end{tabular}

*: significant correlation

Eta squared values in brackets

As shown in table 6, the level of risk exposure, the flood impact, the level of trust in local authorities and the research location influence the residents' evaluations of the danger.

More precisely, the residents who live in higher risk areas feel more endangered for their physical integrity and homes than those living in low or medium risk areas. The same is not true with regard to the evaluations of danger for their village/town. To understand these results we have to consider that in these mountains risk is not "fairly" distributed: the riskiest areas are usually those along the rivers and torrents, which were also the most severely damaged during the events in the years 2000 and 2002. It is precisely in these areas that residents are more conscious of the danger. We can hypothesize that they have a better knowledge of the danger sources because of their proximity with them. At the same time they may have experienced severe damages due to the flood and, as a result, be more sensitive to the hazard.

Another variable which is significantly related to the danger evaluations is the flood impact. This is an index constructed on the basis of six questions by which respondents where requested to evaluate various aspects related to the experienced flood events such as the severity of personal physical damage, psychological problems, stress and tension within the village and the family (for a more precise description see De Marchi et al. 2007). Our results reveal that the more severe the consequences suffered by the residents, the higher their feeling of danger related to flood and flash floods (at community, household and individual level).

Trust in local authorities makes again a difference in the respondents' evaluations: the higher their level of trust, the lower their feeling of danger (see Tab. 6). Again, while this reflects a (correct) positive evaluation of their way of operating, it also signals a tendency to overestimate their capacity of control and possibly a tendency to delegate responsibility. It may be that some residents do not feel endangered because they assume that the management of flood risk is the task of the local services and they rely on their (experienced) efficiency and (supposed) "unlimited capacities" Finally cross tabulation reveals again (as for the previously commented event awareness) that 
residents living in the more isolated and mountainous communities of Vermiglio-Rio Cortina and Bocenago are more worried about the danger.

We also asked respondents to explain why they think that flood and flash floods represent (or not) a danger for their village/town. The justifications provided are numerous and can be grouped as follows (Fig. 2): unpredictability and exceptionality of the events (33.8\%), existence of protection works $(27.5 \%)$, personal/local knowledge of the territory $(19.8 \%)$, and quality of land use planning and management $(12 \%)$.

Fig. 2- Motivations for feeling endangered

\section{Q15 - "Why flash floods/debris flows are/are not a danger for the community?" by evaluation of the danger $(n=400)$}

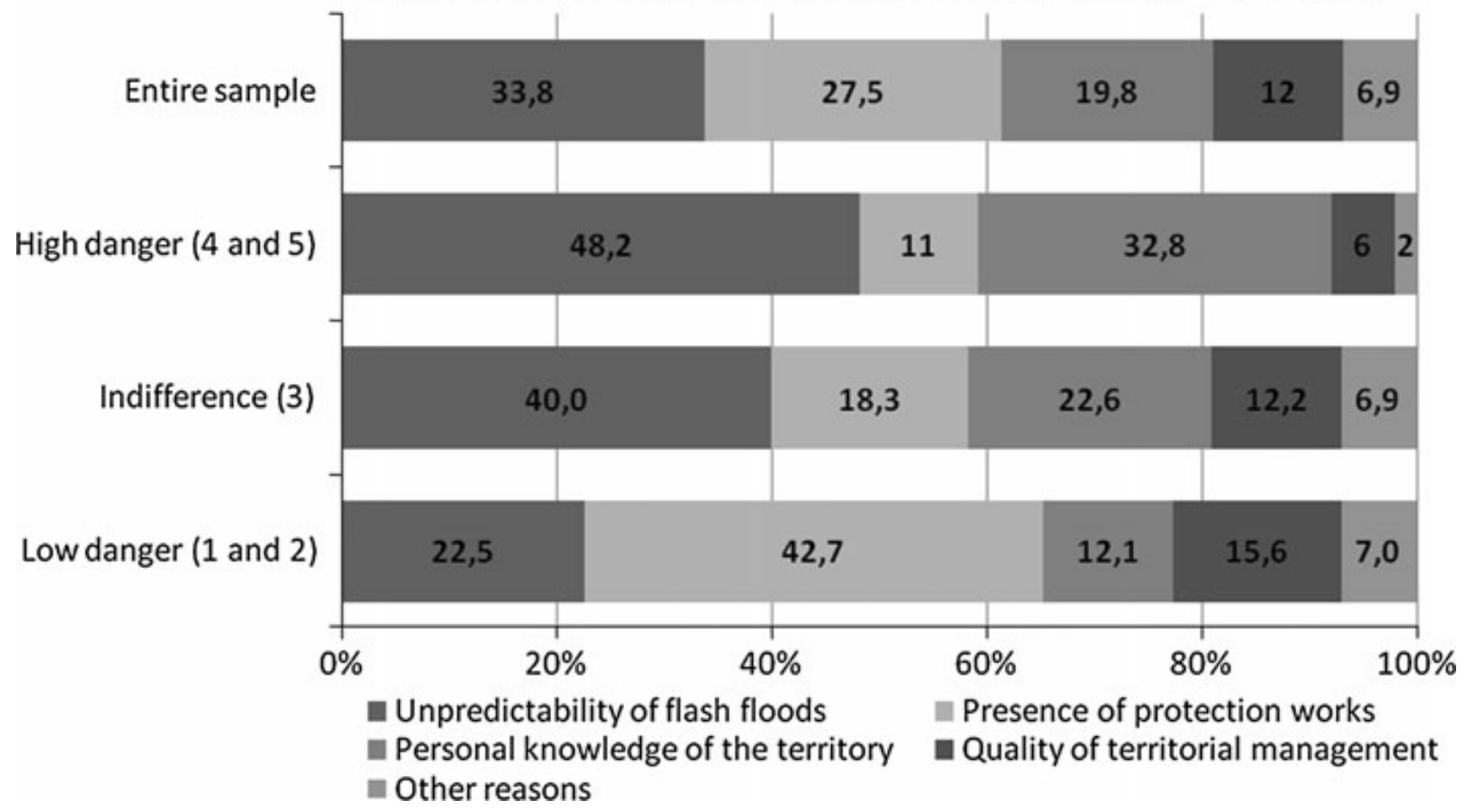

The justifications provided can be fitted (with some approximation) into the frame of cultural theory (Douglas and Wildawsky 1982; Thompson 1990), one of the "classical" approaches in risk perception studies (see section 2). The theory claims that there are four main prototypes of responses to risk: fatalists, egalitarians, hierarchists, and individualists. The respondents who focus on the unpredictability and exceptionality of the events may be considered "fatalists", i.e. belonging to the category of those who consider nature as "capricious" unpredictable and impossible to control. Instead, those who rely on their personal knowledge of the territory may best fit into the group of the "egalitarians", described by cultural theory as those who mistrust experts, consider nature fragile and dependent on human care for conservation. Further, the interviewees who are in favour of an accurate land planning and management can be labelled as "hierarchists", who assume 
that nature is "robust within limits" and ask for precise risk regulations and procedures. One might refer also those who praise technical/engineer solutions to the same category, whereas, on the basis of our questions, we cannot fill the category of the "individualists", those who think nature is "robust" and support individual rational decision making.

By cross tabulating the four justifications provided above with the danger evaluations (see Fig. 2), we realised that those most and least worried about the risk focus on different aspects. More precisely, the latter (i.e. those who score 1 or 2 for danger evaluation and represent $43.5 \%$ of the sample) are more likely to mention technical intervention as a guarantee of safety. They provide answers such as: "Thanks to protection works we are safer"; "The danger exists, as constantly shown by our streams, but I trust structural devices". These sentences reveal the symbolic function of reassurance played by these works, which become "powerful symbols around which the residents place their hopes for a secure future" (Morris and Sinclair 2005: 20). The "levee effect" mentioned previously (Baan and Klijn 2004) is thus at play also in our case studies (see section 2). Carolan (2007) offers an interesting interpretation of this mechanism: "by seeing these structures on a regular basis and witnessing all the previous times that they actually did serve their purpose (holding the water back), individuals come to have a growing confidence in them: 'They've protected us in the past; why would they fail now?"'(Carolan 2007: 46).

The most worried among our respondents (the $25 \%$ of the sample with a score of 4 or 5) mention, as the main motives of worry, the unpredictability and exceptional nature of the events (48.2\%) or alternatively personal knowledge of their environment (32.8\%). For example, they state: "In these mountain areas, floods may always happen"; "There have been several events in the past"; "Elderly people in the village/town told us where the streams might become dangerous". Some respondents even mention some toponyms in local dialects, which embody the memory of past events: for example, Prà dell'Acqua (water meadow), March (rotten soil) and Slavina (flash flood). In so doing they show a solid grounding in their territory: they know its morphology, the location of the dangerous areas, the past experiences with dangerous events.

Overall our results reveal that residents feel little worried about the risk. However some differences are observed in relation to the proximity with the danger source, the level of trust in local authorities, the previous flood experience and their site of residence.

\section{Preparedness and adoption of preparatory measures}

As for risk awareness, even for preparedness we were interested in an evaluation at different levels (individual and community), which had also to be ranked using five point Likert scales. Other 
questions were related to the adoption of private mitigation measures before and/or after the flood events and the willingness to invest money in measures for risk mitigation, such as private works devoted to protect house and property or insurance policies. We asked the respondents to explain the reasons for their answers (in an open-ended form)

As in the case of risk awareness, we detected a hiatus between the evaluations of preparedness at the individual and community level: respondents judge that their communities are more ready to face an event than themselves as individuals (mean scores 3.68 vs. 3.11; Tab. 7).

Tab.7 - Evaluations of preparedness at individual and community level

\begin{tabular}{|l|r|r|}
\hline Questions & $\begin{array}{c}\text { Mean } \\
\text { value }\end{array}$ & $\mathbf{N}^{*}$ \\
\hline [On a scale from 1 (min) to 5 (max)] Presently how well prepared do you feel to face an event? & 3.11 & 381 \\
\hline $\begin{array}{l}\text { [On a scale from } 1 \text { (min) to 5 (max)] Overall, how do you rank the level or preparedness of __ (name } \\
\text { village/town) to face a future event similar to the one of _ ( yyyy)? }\end{array}$ & 3.68 \\
\hline *Don't know" answers have been excluded & 382 \\
\hline
\end{tabular}

Variations can be found according to several independent variables, as shown in table 8.

Tab. 8 - Results of the cross-tabulation between preparedness evaluations and the set of independent variables

\begin{tabular}{|c|c|c|}
\hline & $\begin{array}{l}\text { Personal preparedness to face a } \\
\text { similar event (flash flood/debris flow) }\end{array}$ & $\begin{array}{l}\text { Community preparedness } \\
\text { to face a similar event }\end{array}$ \\
\hline Study site & $*(.045)$ & $*(.079)$ \\
\hline Gender & ${ }^{*}(.057)$ & \\
\hline Community embedding & & $*(.025)$ \\
\hline In fire brigades & $*(.045)$ & \\
\hline Personal preparedness & & $*(.112)$ \\
\hline Trust in local authorities & $*(.017)$ & $*(0.22)$ \\
\hline
\end{tabular}

Eta squared values in brackets

With regard to the research location, in Roverè della Luna, the village which was evacuated, the mean scores for the level of preparedness are the highest at both individual (3.59) and community (4.01) level. For the latter, we hypothesise, even on the basis of focus group discussions with the local fire brigades, that this very positive judgment derives from the very good management of the crises from the part of the agencies in charge, residents give high evaluations about community preparedness. It is more difficult instead to find a reasonable justification for the high evaluations of individual preparedness, unless one thinks of a kind of "halo effect".

The lowest mean values (2.90 and 3.32 respectively) were registered in Romagnano, the location hit in 2000 , with consequences definitely more severe than in the other three study sites. 
In all the four communities we found that the higher is the level of trust in local authorities, the more positive are the evaluations of both personal and community preparedness. In case of personal preparedness variations can be found with regard to gender: men feel more prepared than women (3.44 vs. 2.82). Also, not surprisingly, members of the local fire brigades rank their preparation higher and so do those who share an household with them (26.8\% of the sample overall), the mean value being 4.25 vs. 3.01 for the rest of the sample.

Cross tabulations show significant relations also between community preparedness and "community embedding". The last variable consists in an index which was created by combining a number of questions by which the respondents assessed attitudes of their fellow villagers such as feeling of community belonging, mutual trust, friendship and solidarity. The higher the community level of embedding the higher the evaluation of community preparedness.

The analysis of the justifications provided to the evaluations of preparedness at individual level provides interesting results. Those who feel the least prepared ( 1 and 2 on the Likert scale; $28.1 \%$ of the sample) refer mainly to psychological aspects (26.8\%), specific event characteristics such as their unpredictability (24.1\%) and physical problems (11.6\%). For example they mention a generic fear of future events, irrational reactions, panic attacks (especially if the event happens during the night), disabilities.

On the contrary, those who feel most prepared (4 and 5; 39.3\% of the sample) make reference mainly to organizational aspects $(36.9 \%)$, e.g. knowledge of escape routes or familiarity with those in charge of emergency management. They also mention previous flood experience (29.9\%) and personal training $(8.5 \%)$.

Training is also one of the main justifications for positive judgments about community preparedness at the collective level. Those who judge that their community is highly prepared (score 4 and 5; $60.4 \%$ of the sample ) mention the efficiency of the civil protection services and local voluntary fire brigades based on training and prevention activities, and grounded in continuous cooperation (38.3\%). Reference is also made to previous flood experience (34.6\%), and simulation exercises held in the community $(20.6 \%)$.

This emphasis on logistic-organisational factors, training and simulations reflects the "culture of safety" of the public administrations in this Alpine region. Here the local civil protection services have a very long tradition of efficiency because of their knowledge of the hazard sources in the region, capacity of coordinating efforts in managing emergencies, short term intervention skills. The presence of voluntary fire brigades everywhere is proof that such culture is, or at least was, grounded in the territory. However, as commented previously, there are signs of a tendency to delegate safety to dedicated agencies and services, discarding personal responsibilities. Concerning 
the behaviours aimed to increase self-protection, it is found that the respondents rarely adopt them and not even the experience of the floods was a catalyst for action. Both before and after the events, only a small percentage of inhabitants (3.5\% and $2.5 \%$ respectively) took some measures to protect their households. These include water canalisation, strengthening of cellars and basements, shields with water barriers and walls to protect their houses. On the opposite, those who took no steps to protect their dwelling places (96.5\% and 97.5\% respectively before and after the floods) provided the following justifications: i) no need to take measures, ii) ignorance on what to do and little confidence in available preparatory measures, iii) conviction of living in a safe area either because non risk prone or protected by structural works, iv) belief that flood events are unpredictable and neither occurrence nor damage can be avoided.

The main justifications provided for the lack of adoption of preparatory measures change somewhat with reference to the time before and after the last event(s), as shown in Fig. 3. The presence of structural devices (mostly those recently put in place) is one of the main accounts for not undertaking individual mitigation measures before the event. The so called "levee effect", i.e. faith in the control power of protection works (see section 1) seems definitely to be at play here. For the post-event phase, the reference to protection works (which were actually built after the events in threeout of four communities) is even more frequent (more of the "levee effect"). Also claims to lack of ideas/information on what to do are frequent.

Fig. 3- Motivations for the lack of adoption of protection measures

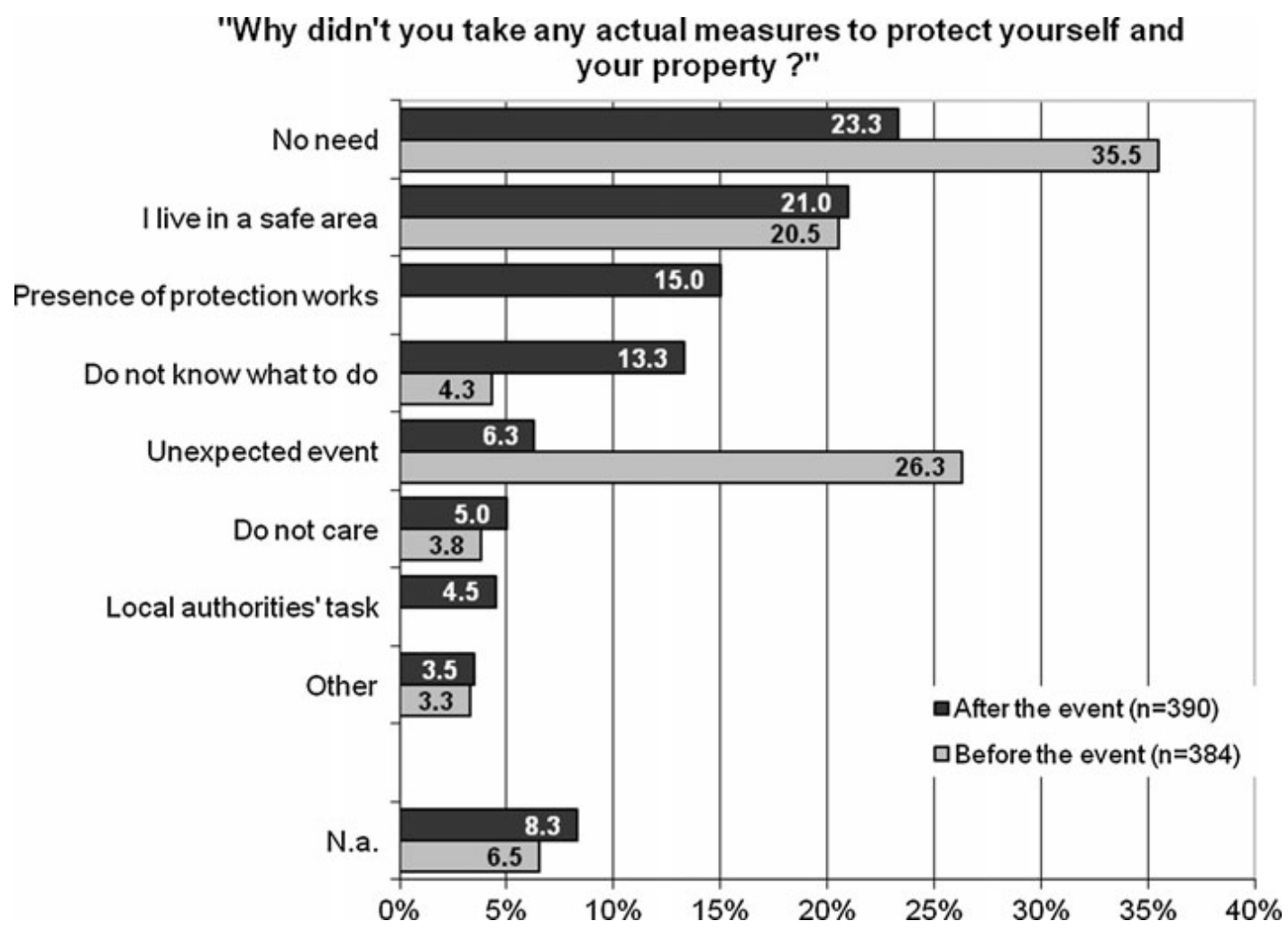


The results from the questions regarding the willingness to invest for safety reveal a discrepancy between attitudes and actual behaviours. We asked respondents about their willingness to invest money either in construction works or in insurance policies (even if in Italy the latter are not presently available) to secure a house located in a risky area. The percentages of positive responses do not differ greatly, for the two options: $62.8 \%$ for construction works and $69.5 \%$ for insurance policies.

Tab. 9- Results of the cross-tabulation between the willingness to invest for safety and the set of independent variables

\begin{tabular}{|l|c|c|}
\hline & $\begin{array}{c}\text { Willingness to invest in construction } \\
\text { works }\end{array}$ & $\begin{array}{c}\text { Willingness to invest in insurance } \\
\text { policies }\end{array}$ \\
\hline Study site & ${ }^{*}(.000)$ & ${ }^{*}(.000)$ \\
\hline Risk exposure & ${ }^{*}(.019)$ & ${ }^{*}(.019)$ \\
\hline Family with persons in need & ${ }^{*}(.032)$ & ${ }^{*}(.008)$ \\
\hline In fire brigade & ${ }^{*}(.007)$ & ${ }^{*}(.010)$ \\
\hline Support index & ${ }^{*}(.003)$ & \\
\hline Trust in local authorities & ${ }^{*}(.011)$ & \\
\hline Flood impact & ${ }^{*}(.002)$ & $*(.000)$ \\
\hline Evacuation & ${ }^{*}(.000)$ & \\
\hline
\end{tabular}

*: significant correlation

Chi square values in brackets

From cross-tabulation, the same independent variables appear significantly related with both items, namely research location, risk exposure, family with persons in need, support index i.e. the level of support received during the event), and evacuation. A higher percentage of respondents are willing to invest money in either construction works or insurance policies in Vermiglio-Rio Cortina (85\% and $88 \%$ respectively) and Bocenago (64\% and 73\% respectively), than in the other two locations (49\% and $56 \%$ respectively in Romagnano and 53\% and $61 \%$ respectively in Roverè della Luna). A stronger orientation to "self-reliance" emerges among the residents in Vermiglio-Rio Cortina and Bocenago who, more frequently than in the other two sites, had adopted some precautionary measures, even before the event. As in the case of risk awareness (see section 4.1) in the two more isolated communities of Vermiglio-Rio Cortina and Bocenago, the residents seem more attentive to risk related issues.

With regard to some other independent variables the results are totally counter-intuitive. We expected more "disadvantaged" respondents (i.e. those living in high risk areas, those who experienced a longer evacuation, those who needed more support in the emergency) to be more prone to invest money for protection and safety. Instead our data show exactly the opposite. Those living in low risk areas, those who did not need support during the event or were not evacuated contemplate the option investments for safety much more frequently than those in a riskier situation 
or with more negative experiences. We may assume that respondents with experience of floods are sceptical about the possibility of preventing damage and/or getting compensation because of previous failures or unsuccessful attempts (by themselves or acquaintances), but of course this hypothesis should be explored further with ad hoc questions.

Finally, the propensity to invest money decreases with the number of "weak" people (small children, elderly, ill) in the household, which may be due not to little concern, but to little availability of money, precisely because of the presence of several dependent persons.

There are some other significant independent variables for the item regarding construction works. In particular the connection with local fire brigades seems important. If someone is a member or if a close kin is enrolled, than he/she shows a higher propensity to invest money for safety in comparison with the rest of the sample ( $85.7 \%$ vs. $64.5 \%)$. Also, not surprisingly those with a low level of trust in local authorities would invest more than the others (74.5\% vs. $60.2 \%)$. Finally, and this time less evidently, those who suffered high flood damage are less willing to invest in construction works (57.9\% vs. $72.1 \%)$, again possibly due to previous failures.

In summary the crucial results presented in this section are the following. First there is a clear discrepancy between the reported attitudes towards self-protection actions and the actual adoption of precautionary measures. From our survey, feeling prepared, being prone to adopting household protective measures, and actually adopting them definitely result as three distinct issues with no clearly identifiable or univocal relations.

Second, only a few independent variables are significantly related to all the respondents' evaluations about preparedness: the research location and the belonging (personal or of close kin) to the local fire brigade. Also the level of trust in local authorities is related to the interviewees evaluations about preparedness ate different levels.

\section{The missing attitude-behavioural link}

One of the aims of our research was to better understand the relationship between risk awareness and preparedness. To this end, we used the cross-tabulation between the sets of variables employed to operationalise these concepts (see section 4.1 and 4.2). We built an index of risk awareness which aggregated the answers about feelings of danger at individual, home and collective level. We crossed it and the other variables gauging risk awareness with the variables used to assess preparedness. The results revealed that there is no statistically significant relationship between risk awareness and preparedness so constructed. Thus knowledge about the level of risk awareness of a certain individual or group is no sufficient to predictor of the actions they will actually take (or do not take) to prevent, or limit the impact of negative occurrences. 
We can identify a number of implications of these results in terms of communication and policy which we will discuss in the following. One of the common assumptions in risk communication studies is that providing new information will influence and possibly increase peoples' both risk awareness and preparedness (Höppner et al 2010; Terpstra et al 2009). Our results about the different conceptual framings of the two issues raise some perplexities about the possibility of "one fit for all" solution and actually help in identifying the different topics and matters on which to focus communication activities.

If we consider risk awareness (see section 4.1), communication activities should aim at unveiling that no structural protection measure is infallible, precisely because of the (largely recognized) unpredictability of certain types of floods/flash floods. Moreover, protecting one site, may increase the exposure of another and the what, where, when and how of an impact can hardly be foreseen with precision. This means, for example, that local authorities should communicate clearly that structural devices do not provide total safety (see also Grothmann and Reusswig 2006), an option which they may not like, as it is basically an open admission of their inability to provide total safety, even when a lot of money is assigned to engineering works. However this seems like a necessary step in order that people take more responsibility for their self-protection. Our results also show that the respondents most aware of the risk focus not only on the unpredictability of the events, but also on their personal knowledge of the environment. Such knowledge should be treated as a resource and its sources and ways of communication explored and exploited. Possibly much insight could be gained in the most isolated communities where the level of risk awareness is definitely higher and adaptation strategies are in place, also derived from oral transmission of past experiences.

Besides considering diffusion of information and knowledge, risk policies should devise ways of strengthening both the formal and informal networks between the residents and the agencies/services in charge of civil protection, relying especially on the voluntary fire brigades corps. This means engaging in a continuous and dynamic process of establishing durable relationships with residents, interest groups, local NGOs, and institutions other than those involved in risk mitigation and management activities(see also Steinführer et al 2009).

As already reported, even a well-established tradition of studies and researches in psychology and social psychology reveals that attitudes are not always good behaviour predictors. At the same time some scholars were able to identify some elements which can foster the attitude-behavioural link. Rosenberg (1968) for example found that attitude stability, strength and resistance to change favour this link. 
Other authors as Ajzen and Fishbein (1980), focus their work on the link between attitudes and behaviours and claim that the most powerful catalysts for action are: i) personal beliefs about the consequences of a certain behaviour and ii) subjective norms, i.e. individual motivations to act. These authors also found that subjective norms are related to the expectation of the group of belonging, which means that there is a strong social component in influencing behavioural decisions. More recent studies (Mucchi Faina 1996; Cialdini 2001) focus on social influence and persuasion mechanisms, e.g. minority or majority group pressures and influences as drivers of actions. These results provide useful insights for our research too. Indeed, in the case of floods, a person may become more motivated, for example to adopt self-protection measures if: i) he/she strongly believes that his/her level of risk exposure is very high; ii) he/she feels strongly endangered; iii) his/her behaviour will have positive consequences (e.g. protection from damages caused by an event); iv) his/her co-villagers expect him/her to adopt these measures or v) some local "leaders", or positive reference individuals adopt them, thus becoming a model also for the others. Especially the hypothesis which underlines the relevance of the strength of risk attitudes in influencing behaviours needs to be tested. In the case of natural hazards this has hardly been the case.

As revealed in the literature cited above, and as it appears also from other data, one cannot expect a full consistency between attitudes and behaviours and moreover, changing strong attitudes is difficult and not necessarily desirable. In the meantime, communication and policy actions aiming at the palingenesis of the citizens are not only incorrect, but potentially dangerous. The task of the authorities and the experts is to work with and for local communities as to promote the emergence of a culture of safety shared by everyone.

\section{Conclusions}

The picture emerging from our results is quite discouraging at first sight. Despite the fact that all the research sites were impacted by severe events in the past, less than half respondents were expecting that similar ones might happen again. Local residents are not very concerned about the danger and do not take into serious consideration the possibility of being personally at risk. There is a hiatus between the evaluation of personal and community risk, with an inclination to underestimate the former. The residents living in the isolated communities, in higher risk areas, those who suffered more the impact of the recent floods and with a lower level of trust in local authorities are in general more worried about the danger than the others.

Feeling more or less endangered is also linked to the conceptual framing of the risk. The least concerned concentrate mainly on the presence of structural devices, whereas the most concerned 
focus on the unpredictability and exceptionality of the events, as well as on personal knowledge of the territory and its danger sources. Our results also reveal a tendency to delegate the responsibility for safety to the agencies in charge, with a lack of personal involvement and agency.

Paradoxically the good performance of the dedicated services in this Alpine region may encourage a residents' progressive disengagement with self-protection. Arguably this can be the case in other areas and other countries, as well as with other risk issues and in that sense our research results can be generalized, if not strictu sensu, as hints of certain common tendencies. To a large extent, the language and the culture of risk, distinctive of expert groups seem to have totally supplanted those of danger, familiar to lay people. The challenge is to integrate them instead, so that the unprecedented amount of knowledge derived from technical risk assessment and the increased control of adverse effects obtainable by means of structural works are supplemented by the folk wisdom and skills accumulated by experience and transmitted from one generating to the next. What Benessia and colleagues wrote with reference to sustainability, is definitely applicable also to risk prevention and management: "Working today on this heritage is not a merely philological act or a nostalgic reminder of the 'good old times' but a way to bring to life and experience a whole variety of possible complex and embodied insights about the relationship between human beings and their cultural and natural environments " (Benessia et al. 2012 forthcoming) .

Hybridization of language and cultures, rather than substitution seems to be worth pursuing. "Residual risk", an esoteric expression (and concept) becomes familiar when formulated in terms of danger or threat, something any human being cannot totally avoid or control and still must live with. The analysis also indicates the limited impact of the official information initiatives already at place (as simulation exercises, communication activities, emergency plans), suggesting that informal sources of information and knowledge are very important. Better knowledge of one's environment is important and as important is the existence of local support networks as key elements for both effective preparedness and response (Thrush et al. 2005). Our chances for survival, as individuals, communities and organised societies always resided and still resides in integration and collaboration, not in delegation of responsibility to a few, even if supposedly the most knowledgeable ones. 


\section{Acknowledgement}

The research was funded by the EC Sixth Framework Programme funded project FLOODsite (http://www.floodsite.net) Contract GOCE-CT-2004-505420. ISIG and the Univerisy of Padova were partners of the project. At the time of the research Bruna De Marchi and Anna Scolobig were both associated with ISIG. We wish to thank all the colleagues who provided us with professional advice and collaboration, the key informants in the provinces of Trento and Bolzano/Bozen, who devoted their time to our interviews and focus groups, the interviewers who conducted the surveys in Bocenago, Romagnao, Roveré della Luna and Vermiglio-Rio Cortina, and, last but not least, the survey respondents. 


\section{References}

Ajzen I, Fishbein M (1980) Understanding attitudes and predicting social behavior. Blackwell, London

Baan P, Klijn F (2004) Flood risk perception and implications for flood risk management in the Netherlands. International Journal of River Basin Management 2: 113-122

Beatley T (1989) Towards a moral philosophy of natural disaster mitigation. International Journal of Mass Emergencies and Disasters 7: 5-32

Beatley T (1999) Ethical dilemmas in hazard mitigation. Darby PA, DIANE Publishing Co

Beck U (1992) Risk society: toward a new modernity. Sage, London

Benessia A, Funtowicz S, Bradshaw S, Ferri F, Ra'ez-Luna EF, Medina C.P (2012 forthcoming) Hybridizing sustainability: towards a new praxis for the present human predicament. Sustainability Science, doi 10.1007/s11625-011-0150-4.

Borga M, Anagnostou EN, Blöschl G, Creutin JD (2010): Flash Floods: observations and analysis of hydrometeorological controls. J. of Hydrology, 394, (1-2), 1-3, doi:10.1016/j.jhydrol.2010.07.048.

Borga M, Anagnostou EN, Blöschl G, Creutin JD (2011) Flash flood forecasting, warning and risk management: the HYDRATE project. Environmental Science \& Policy 14: 834-844

Burby R, French S (1981) Coping with floods: the land use management paradox. Journal of the American Planning Association 47: 289-300

Burningham K, Fielding J, Thrush J (2008) It'll never happen to me: understanding public awareness of local flood risk. Disasters 31: 216-238

Bye P, Horner M, Easter 1998 floods (1998) Report by the independent review team to the board of environment agency. Environment Agency 1, London

Carolan M (2007) The precautionary principle and traditional risk assessment: Rethinking how we assess and mitigate environmental threats. Organisation \& Environment 20: 5-24

Cave B, Cragg L, Gray J, Parker D, Pygott K, Tapsell S (2009) Understanding of and response to severe flash flooding, UK Environment Agency, DEFRA, Bristol.

Cialdini R B (2001) Influence: Science and practice. Harper-Collins, New York

Creutin, JD, Borga M, Lutoff C, Scolobig A, Ruin I, Creton-Cazanave C (2009) Catchment dynamics and social response during flash floods: The potential of radar rainfall monitoring for warning procedures. Meteorological Applications, 16: 115-125, .DOI: 10.1002/met.128; http://dx.doi.org/10.1002/met.128.

De Marchi B, Pellizzoni L, Greco S (2003) Risk as social construct, working paper 2 for Food risk communication and consumer's trust in the food supply chain. (http://eprints.unifi.it/archive/00000747/20/wp2 ISIG_risk as social_construct-r.pdf)

De Marchi B, Scolobig A, Delli Zotti G, Del Zotto M (2007) Risk construction and social vulnerability in an Italian Alpine Region. Report T11-07-12 of FLOODsite Integrated Project, available at http://www.floodsite.net/html/publications2.asp?ALLdocs $=$ on \&Submit=View (last access: 09 August 2009)

Deeming H (2008) Increasing resilience to storm surge flooding: risks, social networks and local champions, in Samuels P, Huntington S, Allsop W, Harrop J (eds.) Flood Risk Management: Research and Practice, CRC Press, Taylor and Francis Group, London (Proceedings of the European Conference on Flood Risk Management. Research into Practice, Oxford, UK 30 Sept 2 Oct 2008), Also in CD-Rom. Leiden: CRC Press/Balkema: 945-955 
Douglas M (1985) Risk acceptability according to social sciences. Routledge, London

Douglas M, Wildavsky A (1982) Risk and culture. University of California Press, Berkeley

Dynes R (1974) Organised behaviour in disasters. Ohio State University Press, Columbus

Eagly A, Chaiken S (1993) The psychology of attitudes. HBJ, London

Enserink B (2004) Thinking the unthinkable- the end of the Dutch river dike system? Exploring a new safety concept for the river management. Journal of Risk Research 7: 745-757

Fazio R, Williams C (1986) Attitude accessibility as a moderator of the attitude-perception and attitude-behaviour relations: An investigation of the 1984 presidential election. Journal of Personality 51: 505-514

Fink A, Ulbrich U, Engel H (1996) Aspects of the January 1995 flood in Germany. Weather 51: 3439

Fischhoff B, Bostrom A, Quadrel M (1993) Risk perception and communication. Annual Review of Public Health 14: 183-203

Fischhoff B, Slovic P, Lichtenstein S (1979) Which risks are acceptable? Environment 21: 17-38

Floyd D, Prentice-Dunn S, Rogers RW (2000) A meta-analysis of research on protection motivation theory. Journal of Applied Social Psychology 30: 407-429

Fordham M (1992) Choice and Constraint in Flood Hazard Mitigation: The environmental attitudes of floodplain residents and engineers, PhD Dissertation, Middlesex University, 1992.

Giddens A (1990) The Consequences of Modernity, Polity, Cambridge

Green C, Tunstall S, Fordham M (1991) The risks from flooding: Which risks and whose perception? Disasters 15: 227-236

Grothmann T, Reusswig F (2006) People at risk of flooding. Why some residents take precautionary action while others do not. Natural Hazards 38: 101-120

Gruntfest (1987) Warning dissemination and response with short lead times. British and International Perspectives, edited by Handmer J, GEO Books Norwich UK: 191-206

Handmer J (2000) Improving flood warning in Europe: a research and policy agenda. Environmental Hazard 3: 19-28

Harries T (2008) Feeling secure or being secure? Why it can seem better not to protect yourself against a natural hazard. Health, Risk and Society 10:479-490

Hoekstra A (1998) Appreciation of water: four perspectives. Water Policy 1: 605-622

Höppner C, et al (2010) Risk communication and natural hazards, Research Report, Del. 5.1., CapHaz-Net Social capacity building for natural hazards - Toward more resilient societies, European Commission $6^{\text {th }}$ Framework Programme http://caphaz-net.org/outcomesresults/CapHaz-Net_WP5_Risk_Communication.pdf.

ISTAT (Istituto Nazionale di Statistica) (2001) $14^{\circ}$ Censimento Generale della Popolazione e delle Abitazioni'. ISTAT, Roma

Jasanoff S (1998) The political science of risk perception. Reliability Engineering and Systems Safety 59: 91-99.

Johnson B, Covello V (1987) The social and cultural construction of risk. Reidel, Dordrecht

Kundzewicz Z, Mendel L (2003) Flood risk and vulnerability in the changing world, International conference: Towards natural flood reduction strategies, Warsaw

La Piere R (1934) Attitudes versus action. Social Forces 13: 230-237 
Lindell M, Whitney D (2000) Correlates of household seismic hazard adjustment adoption. Risk Analysis 20: 13-25

Llasat M, Siccardi F (2010) A reflection about the social and technological aspects in flood risk management - the case of the Italian Civil Protection, Nat. Hazards Earth Syst. Science 10: 109-119, www.nat-hazards-earth-syst-sci.net/10/109/2010/

Marchi L, Borga M, Preciso E, Gaume E (2010) Characterisation of selected extreme flash floods in Europe and implications for flood risk management. J. of Hydrology, 394: 118-133. doi:10.1016/j.jhydrol.2010.07.017.

Marradi (2007) Metodologia delle scienze sociali. Il Mulino, Bologna

Marsh K, Wallace H (2005) The influence of attitudes on beliefs: formation and change: 369-397, in Albarracin D, Johnson B, Zanna (eds), The handbook of attitudes, Mahwah, New York

McCarthy S, Penning-Rowsell E, Tunstall S (2008) Public attitudes to 'community based' small scale flood risk reduction measures in England: A case study in the Lower Thames catchment in Bosher L.S. (ed.), Hazards and the Built Environment: Attaining Built-in Resilience, Taylor \& Francis, London

Miceli R, Sotigiu I, Settanni M (2008) Disaster preparedness and perception of flood risk: a study in an alpine valley in Italy. Journal of Environmental Psychology 28: 164-173

Mileti D, Brien P (1992) Warnings during disaster: normalizing communicated risk. Social Problems 39: 40-57

Misztal B (1996) Trust in Modern Societies. Polity Press, Cambridge

Morris-Oswald O, Sinclair T (2005) Values and floodplain management: case studies from the Red River Basin, Canada. Environmental Hazards 6: 9-22

Mucchi Faina G (1996) L'influenza sociale. Il Mulino, Bologna

Neuwirth K, Dunwoody S, Griffin R (2000) Protection motivation and risk communication. Risk Analysis 20: 721-734

Norbiato D, Borga M, Degli Esposti S, Gaume E and Anquetin S, (2008) Flash flood warning based on rainfall depth-duration thresholds and soil moisture conditions: An assessment for gauged and ungauged basins. J. Hydrology, 362: 274-290, 10.1016/j.jhydrol.2008.08.023.

Parker D, Priest S, McCarthy S (2011) Exploring surface water flood warning requirements and potential in England and Wales. Applied Geography, 31: 891-900

Paton D, Smith L, Johnston D (2000) Volcanic hazards: risk perception and preparedness. New Zeland Journal of Psychology 29: 84-88

Peek L, Mileti D (2002) The history and future of disaster research. In Betchell A, Churchmann S, Handbook of environmental psychology, John Wiley and Sons, New York: 511-524

Petty R, Krosnick J (1995) Attitude strength: antecedents and consequences, Mahwah, New York, Lawrence Erlbaum

Plapp T (2001) Perception and evaluation of natural risks. Institute for Insurance of the University of Karlsruhe, Karlsruhe

Plapp T, Werner U (2006) Understanding risk perception from natural hazards: examples from Germany. Risk, 21:101-108

Renn O (2008) Risk governance. Coping with uncertainty in a complex world. Earthscan, London

Renn O, Rohrmann B (2000) Cross-cultural risk perception research: state and challenges. In Renn O, Rohrmann B, eds. Cross-cultural risk perception: a survey of empirical studies. Kluwer, Dordrecht 
Rosenberg M (1968) Mathematical models of social behavior. In Lindzey G, Aronson A (Eds.), The handbook of social psychology, Vol. 1. Massachusetts: Addison-Wesley.

Ross M, Mcfarland C, Fletcher G (1981) The effect of attitude on the recall of personal histories. Journal of Personality and Social Psychology 40: 627-634.

Ruin I, Creutin J-D, Anquetin S, Lutoff C (2008) Human exposure to flash-floods - relation between flood parameters and human vulnerability during a storm of September 2002 in Southern France. Journal of Hydrology, doi: 10.1016/j.jhydrol.2008.07.044.

Scolobig A (2008) Le dinamiche sociali del rischio e della vulnerabilità. L'esperienza di Malborghetto-Valbruna [The social dynamics of risk and vulnerability. The MalborghettoValbruna case-study], PhD Dissertation, Udine University

Scolobig A, Castan-Broto V, Zabala A (2008) Integrating multiple perspectives in social multicriteria evaluation of flood mitigation alternatives. The case of Malborghetto-Valbruna. Environment and Planning C: Government and Policy 26: 1143-1161

Siegrist M, Gutscher H (2008) Natural hazards and motivation for mitigation behavior: people cannot predict the affect evoked by a severe flood. Risk Analysis 28: 771- 778

Skiple Ibreek A, Krasovkaia I, Gottschalk L, Berg H (2005) Perception and communication of flood risk - preliminary results from the flows project, International Conference on Innovation Advances and Implementation of Flood Forecasting Technology, Norway

Slovic P (1987) Perception of risk. Science 236: 280-285

Slovic P (2000) The perception of risk. Earthscan, London

Starr C (1969) Social benefit versus technological risk: what is our society willing to pay for safety? Science 165: 1232-1238

Stefanovic D (2003) The contribution of philosophy to hazard assessment and decision making. Natural Hazards 28: 229-247

Steinführer A, De Marchi B, Kuhlicke C, Scolobig A, Tapsell S, Tunstall S (2009) Vulnerability, resilience and social constructions of flood risk in exposed communities. A cross-country comparison of case studies in Germany, Italy and the UK, Report T11-07-12 of FLOODsite Integrated Project, Helmholtz Centre for Environmental Research - UFZ, Leipzig

Steinführer A, Kuhlicke C (2007) Social vulnerability and the 2002 flood. Country report Germany (Mulde river). Report T11-07-08 of FLOODsite Integrated Project, http://www.floodsite.net/html/publications2.asp?ALLdocs $=$ on\&Submit=View

Steinführer A, Kuhlicke C, De Marchi B, Scolobig A, Tapsell S, Tunstall S (2009), Local communities at risk from flooding: social vulnerability, resilience and recommendations for flood risk management in Europe. Helmholtz Centre for Environmental Research - UFZ, Leipzig http://www.ufz.de/data/Task11_Broschuere 7-0911060.pdf.

Strydom P (2002) Risk, environment and society. Open University Press, Buckingham.

Tapsell, S.M. and Tunstall, S.M. (2008) 'I wish I'd never heard of Banbury': the relationship between 'place' and the health impacts of flooding'. Health \& Place 14: 133-154.

Tapsell SM, Penning-Rowsell EC, Tunstall SM, Wilson TL (2002) Vulnerability to flooding: Health and social dimensions. Philosophical Transactions of the Royal Society A: Mathematical, Physical and Engineering Sciences, 360 (1796), 1511-1525.

Terpstra T, Lindell M, Gutteling J (2009) Does communicating (flood) risk affect (flood) risk perceptions? Results of a quasi-experimental study. Risk Analysis 29: 1141- 1155

Thrush D, Burningham K, Fielding J (2005) Exploring flood-related vulnerability: A qualitative study. Environment Agency R and D Report W5C-018/3 Bristol: Environment Agency ISBN 1 844324206. 
Tierney K, Lindell M, Perry L (2001) Facing the Unexpected. Disaster Preparedness and Response in the United States. Joseph Henry Press, Washington

Wachinger G, Renn O, Bianchizza C, Coates T, De Marchi B, Domènech L, Jakobson I, Kuhlicke C, Lemkow L, Pellizzoni L, Piriz A, Saurí D, Scolobig A, Steinführer A, Supramaniam M, Whittle R (2010), Risk perception and natural hazards, Research Report, Del. 5.1., CapHaz-Net Social capacity building for natural hazards - Toward more resilient societies, European Commission $7^{\text {th }} \quad$ Framework Programme http://caphaz-net.org/outcomes-results/CapHazNet_WP3_Risk_Perception.pdf, 111 pp

Weinstein N, Lyon J, Rothman A, Cuite C (2000) Preoccupation and affect as predictors of protective action following natural disaster. British Journal of Health Psychology 5: 351-363 
